\title{
ESTIMASI PARAMETER MODEL SURVIVAL DISTRIBUSI RAYLEIGH PRIOR UNIFORM DENGAN METODE BAYESIAN SELF
}

\author{
Eka Rizki Wahyuni, Setyo Wira Rizki, Hendra Perdana
}

\begin{abstract}
INTISARI
Data survival adalah data yang menjelaskan tentang waktu suatu individu atau objek dapat bertahan hingga terjadinya suatu kejadian. Penelitian ini menggunakan metode Bayesian dengan pendekatan Squared Error Loss Function (SELF) untuk melakukan estimasi parameter pada model survival. Proses estimasi parameter metode Bayesian SELF memerlukan informasi dari fungsi likelihood dan distribusi prior yang kemudian akan membentuk distribusi posterior. Hasil dari estimasi parameter metode Bayesian SELF diterapkan pada data kasus penderita kanker paru-paru untuk mengetahui peluang bertahan hidup pasien penderita kanker paru-paru. Kesimpulan dari penelitian ini adalah hasil dari estimasi parameter distribusi Rayleigh prior Uniform dengan menggunakan metode Bayesian SELF menghasilkan nilai survival pada hari ke-95 sebesar 0,929056666 dan nilai hazard 1,549169 $\times 10^{-3}$ sedangkan hari ke-791 menghasilkan nilai survival sebesar

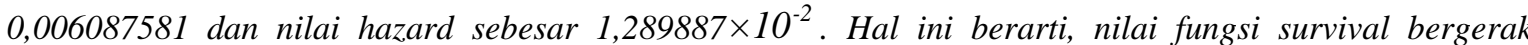
mendekati nol sesuai dengan karakteristik fungsi survival dan fungsi hazard yang bergerak naik mendekati satu sesuai dengan karakteristik distribusi Rayleigh.
\end{abstract}

Kata Kunci: Survival, Rayleigh, Bayesian, SELF.

\section{PENDAHULUAN}

Analisis survival adalah proses analisis statistika untuk menganalisis data dengan variabel yang memperhatikan waktu awal hingga waktu terjadinya suatu kejadian[1]. Waktu survival yaitu hal yang menunjukkan seberapa lama individu dapat bertahan terhadap sesuatu, selama dilakukannya pengamatan. Tiga faktor yang dibutuhkan dalam menentukan waktu survival, pertama yaitu waktu awal pencatatan (start point) yang terdefinisi dengan baik. Kedua, waktu akhir pencatatan (end point) yang terdefinisi dengan baik, dan ketiga yaitu skala pengukuran sebagai bagian dari waktu yang harus jelas[2].

Terdapat dua model yang digunakan dalam analisis survival, yaitu model non-parametrik dan model parametrik. Model non-parametrik digunakan jika data tidak mengikuti asumsi tertentu. Model parametrik digunakan jika data mengikuti asumsi suatu distribusi tertentu. Penelitian ini menggunakan model parametrik, distribusi yang digunakan adalah distribusi Rayleigh. Distribusi Rayleigh merupakan bentuk khusus dari distribusi Weibull dua parameter. Model parametrik memiliki dua metode yang dapat digunakan dalam menganalisis data survival, yaitu metode Klasik dan metode Bayesian. Salah satu contoh dari metode Klasik adalah Maximum Likelihood Estimation (MLE). Metode Bayesian memandang parameter sebagai variabel yang menggambarkan pengetahuan awal tentang parameter sebelum pengamatan dilakukan dan dinyatakan dalam suatu distribusi yang disebut dengan distribusi prior[3].

Informasi dalam distribusi prior dikombinasikan dengan informasi sampel yang dinyatakan dengan fungsi likelihood. Hasil dari kombinasi tersebut dinyatakan dalam bentuk distribusi yang disebut distribusi posterior. Terdapat beberapa pendekatan dalam metode Bayesian, yaitu Linear Exponential Loss Function (Linex), General Entropy Loss Function (GELF), Lindley Approximation, dan Squared Error Loss Function (SELF). Pendekatan yang paling umum digunakan dalam estimasi parameter metode Bayesian adalah pendekatan SELF [4]. Distribusi posterior selanjutnya digunakan dalam estimasi parameter dengan metode Bayesian SELF. 
Penelitian ini bertujuan untuk menentukan estimasi parameter model survival berdistribusi Rayleigh dengan prior Uniform menggunakan metode Bayesian SELF. Hasil dari estimasi parameter tersebut diterapkan pada data kasus penderita kanker paru-paru yang diperoleh dari software R-3.5.1. Data yang sudah didapatkan, diuji menggunakan Kolmogorov-Smirnov dengan bantuan software EasyFit untuk mengetahui bahwa data berdistribusi Rayleigh. Langkah selanjutnya adalah menentukan fungsi distribusi kumulatif, fungsi survival, dan fungsi hazard dari distribusi Rayleigh. Selanjutnya adalah menentukan fungsi likelihood, yang kemudian dikombinasikan dengan distribusi prior Uniform untuk mendapatkan distribusi posterior. Distribusi posterior kemudian digunakan untuk menentukan estimasi parameter pada pendekatan SELF, yang selanjutnya diterapkan pada data kasus penderita kanker paru-paru.

\section{DISTRIBUSI RAYLEIGH}

Distribusi Rayleigh pertama kali dikenalkan pada tahun 1880 oleh seorang ahli fisika yang berasal dari Inggris, yaitu Baron John William Strutt Rayleigh. Distribusi Rayleigh merupakan bentuk khusus dari distribusi Weibull dua parameter[5]. Karakteristik dari distribusi Rayleigh adalah fungsi hazard yang naik secara linear terhadap waktu[6]. Fungsi kepadatan peluang distribusi Rayleigh dinyatakan sebagai berikut:

$$
f(t ; \theta)=\frac{t}{\theta^{2}} \exp \left(-\frac{t^{2}}{2 \theta^{2}}\right) \quad ; t \geq 0, \theta>0
$$

didefinisikan, $t$ merupakan data waktu dan $\theta$ merupakan parameter.

Berdasarkan fungsi kepadatan peluang dari distribusi Rayleigh, maka fungsi distribusi kumulatif untuk distribusi Rayleigh adalah:

$$
F(t ; \theta)=1-\exp \left(-\frac{t^{2}}{2 \theta^{2}}\right)
$$

Berdasarkan Persamaan (2), dapat ditentukan fungsi survival dan fungsi hazard sebagai berikut:

$$
\begin{aligned}
& s(t ; \theta)=\exp \left(-\frac{t^{2}}{2 \theta^{2}}\right) \\
& h(t ; \theta)=\frac{t}{\theta^{2}}
\end{aligned}
$$

\section{ESTIMASI PARAMETER METODE BAYESIAN SELF}

Estimasi parameter menggunakan metode Bayesian memerlukan fungsi likelihood dari distribusi Rayleigh, yaitu:

$$
\begin{aligned}
L\left(t_{i} ; \theta\right) & =\prod_{i=1}^{n}\left[f\left(t_{i} ; \theta\right)\right] \\
& =\left(\frac{\prod_{i=1}^{n} t_{i}}{\theta^{2 n}}\right)\left(\exp \left(-\frac{\sum_{i=1}^{n} t_{i}^{2}}{2 \theta^{2}}\right)\right)
\end{aligned}
$$

Setelah menentukan fungsi likelihood, dilanjutkan dengan menentukan distribusi posterior dengan mengkombinasikan fungsi likelihood dan distribusi prior. Distribusi prior adalah distribusi dari parameter sebelum ada data yang diteliti, dan dinotasikan dengan $p(\theta)$ [4]. Pada umumnya prior yang dipilih adalah berdasarkan pada pengetahuan dan kepercayaan subjektif peneliti[7]. Apabila peneliti tidak ingin memasukkan keyakinan pribadi dalam pengambilan keputusan, menjadi objektif dan ingin memberikan bobot yang sama untuk semua kemungkinan keberhasilan, maka peneliti dapat menggunakan prior Uniform [3]. Distribusi prior Uniform dinyatakan sebagai berikut: 


$$
p(\theta)=\frac{1}{b-a} \quad ; a<\theta<b
$$

sehingga, dapat ditentukan distribusi posterior dengan mengkombinasikan Persamaan (5) dan Persamaan (6), sebagai berikut:

$$
\begin{aligned}
\pi^{*}\left(\theta \mid t_{i}\right) & =\frac{p(\theta) L\left(t_{i} ; \theta\right)}{\int_{0}^{\infty} p(\theta) L\left(t_{i} ; \theta\right) d \theta} \\
& =\frac{\frac{1}{\theta^{2 n}}\left(\exp \left(-\frac{\sum_{i=1}^{n} t_{i}^{2}}{2 \theta^{2}}\right)\right)}{-\left(\sum_{i=1}^{n} t_{i}^{2}\right)^{\frac{1}{2}-n}\left(2^{n-\frac{3}{2}}\right) \Gamma\left(n-\frac{1}{2}\right)}
\end{aligned}
$$

Setelah menentukan distribusi posterior, dilanjutkan dengan melakukan estimasi parameter dengan metode Bayesian SELF, SELF didefinisikan sebagai berikut:

$$
\mathcal{L}\left(\hat{\theta}_{B S}, \theta\right)=\left(\hat{\theta}_{B S}-\theta\right)^{2} \quad ; 0<\theta<\infty
$$

dengan $\hat{\theta}_{B S}$ merupakan parameter dari metode Bayesian SELF. Estimasi parameter metode Bayesian SELF dapat diperoleh dengan meminimumkan ekspektasi loss function, yaitu:

$$
\frac{\partial\left[E\left(\left(\hat{\theta}_{B S}-\theta\right)^{2}\right)\right]}{\partial \theta}=0
$$

dengan demikian diperoleh

$$
E(\theta)=\hat{\theta}_{B S}
$$

Berdasarkan Persamaan (8), dapat ditentukan estimasi parameter dengan metode Bayesian SELF, yaitu:

$$
\begin{aligned}
\hat{\theta}_{B S}=E(\theta) & =\int_{0}^{\infty} \theta \cdot \pi^{*}\left(\theta \mid t_{i}\right) d \theta \\
& =\frac{\Gamma(n-1)}{\left(\sum_{i=1}^{n} t_{i}^{2}\right)^{\frac{1}{2}}\left(2^{\frac{1}{2}}\right) \Gamma\left(n-\frac{1}{2}\right)}
\end{aligned}
$$

Berdasarkan Persamaan (9), dapat ditentukan fungsi survival dan fungsi hazard dengan estimasi parameter metode Bayesian SELF adalah:

$$
\begin{aligned}
\hat{S}_{B S}\left(t_{i} ; \hat{\theta}_{B S}\right) & =\exp \left(-\frac{t_{i}^{2}}{2 \theta^{2}}\right) \\
& =\exp \frac{-t_{i}^{2}}{2\left(\frac{\Gamma(n-1)}{\left(\sum_{i=1}^{n} t_{i}^{2}\right)^{\frac{1}{2}}\left(2^{\frac{1}{2}}\right) \Gamma\left(n-\frac{1}{2}\right)}\right)^{2}}
\end{aligned}
$$




$$
\begin{aligned}
\hat{h}_{B S}\left(t_{i} ; \hat{\theta}_{B S}\right) & =\frac{t_{i}}{\theta^{2}} \\
& =\frac{t_{i}}{\left(\frac{\Gamma(n-1)}{\left(\sum_{i=1}^{n} t_{i}^{2}\right)^{\frac{1}{2}}\left(2^{\frac{1}{2}}\right) \Gamma\left(n-\frac{1}{2}\right)}\right)^{2}}
\end{aligned}
$$

\section{STUDI KASUS}

Data yang digunakan merupakan data waktu bertahan hidup pasien kanker paru-paru dari North Central Cancer Treatment Group. Data kasus penderita kanker paru-paru ini diambil dari software R3.5.1. Dalam penelitian ini, digunakan variabel waktu dengan lama waktu penelitian adalah 791 hari. Data kasus penderita paru-paru yang didapat berjumlah 1022 hari penelitian, namun data awal yang didapatkan tidak berdistribusi Rayleigh, sehingga dilakukan pemotongan data berdasarkan pada satuan hari. Setelah melakukan beberapa kali percobaan, data berdistribusi Rayleigh dengan jumlah 791 hari. Data yang digunakan dalam penelitian ini harus berdistribusi Rayleigh, agar data dapat digunakan untuk analisis survival. Uji yang digunakan untuk mengetahui bahwa data berdistribusi Rayleigh adalah uji Kolmogorov-Smirnov. Hipotesis uji yang digunakan sebagai berikut:

$H_{0}$ : data mengikuti distribusi Rayleigh

$H_{1}$ : data tidak mengikuti distribusi Rayleigh

dengan taraf signifikansi $\alpha=5 \%$ atau $\alpha=0,05$. Apabila nilai $p$-value lebih kecil dari $\alpha$, maka $H_{0}$ ditolak.

Uji Kolmogorov-Smirnov dilakukan dengan bantuan software EasyFit, dengan hasil sebagai berikut:

Tabel 1 Output EasyFit Kolmogorov-Smirnov

\begin{tabular}{|c|c|}
\hline \multicolumn{2}{|c|}{ Kolmogorov-Smirnov } \\
\hline Sample Size & 220 \\
P-Value & 0,15106 \\
\hline
\end{tabular}

Dari Tabel 1, dapat disimpulkan bahwa data kasus penderita kanker paru-paru memiliki $p$-value lebih besar dari $\alpha$ yaitu $0,15106>0,05$ sehingga $H_{0}$ tidak ditolak, yang artinya data berdistribusi Rayleigh. Jumlah sampel adalah sebanyak 220 pasien.

Penentuan nilai dari parameter $\hat{\theta}_{B S}$ dilakukan dengan bantuan software R. Berdasarkan Persamaan (8), dihasilkan bahwa nilai parameter $\hat{\theta}_{B S}$ adalah 247,6352. Analisis dilanjutkan dengan menghitung nilai survival dan nilai hazard dari metode Bayesian SELF. Hasil perhitungan dengan menggunakan software R-3.5.1 adalah sebagai berikut:

Tabel 2 Nilai Survival dan Nilai Hazard

\begin{tabular}{ccc}
\hline Waktu & Survival BS & Hazard BS \\
\hline 95 & 0,929056666 & $1,549169 \times 10^{-3}$ \\
201 & 0,719347677 & $3,277716 \times 10^{-3}$ \\
300 & 0,480073017 & $4,892114 \times 10^{-3}$ \\
477 & 0,156427454 & $7,778461 \times 10^{-3}$ \\
588 & 0,059663690 & $9,588543 \times 10^{-3}$ \\
689 & 0,020844845 & $1,123555 \times 10^{-2}$ \\
705 & 0,017378790 & $1,149647 \times 10^{-2}$
\end{tabular}


791 0,006087581

$1,289887 \times 10^{-2}$

Berdasarkan Tabel 2, dapat dilihat nilai survival yang terus turun hingga bernilai 0,006087581 pada hari ke 791, sedangkan nilai hazard semakin besar dan bernilai $1,289887 \times 10^{-2}$ pada hari ke 791 .

Berdasarkan nilai survival dan nilai hazard pada Tabel 2, grafik yang dibentuk untuk nilai survival dan nilai hazard adalah sebagai berikut:

Survival

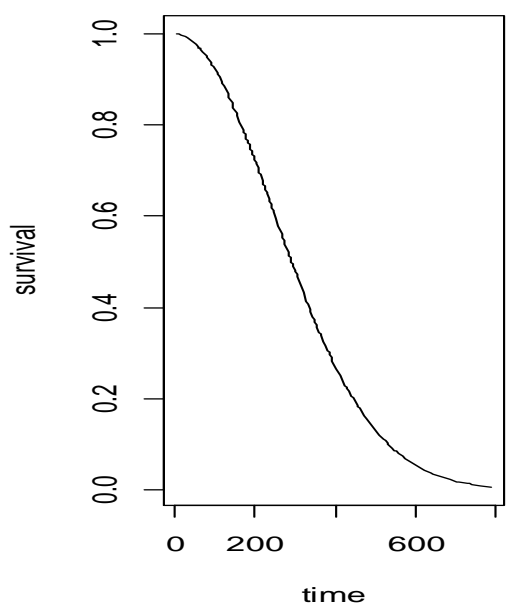

(a)

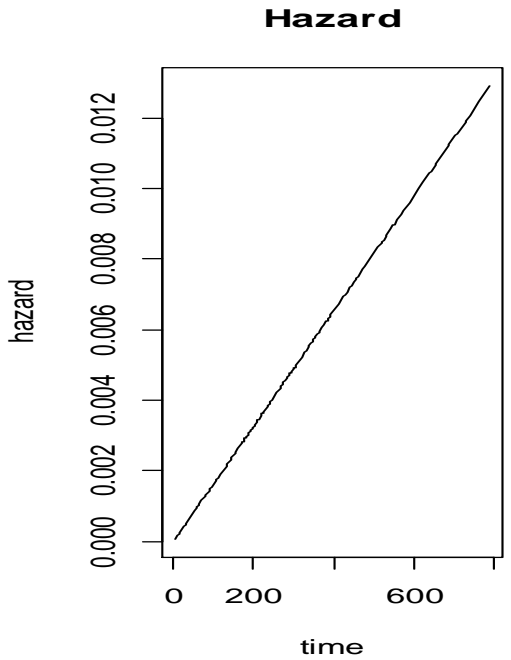

(b)

Gambar 1. Grafik Nilai Survival dan Nilai Hazard

Berdasarkan Gambar 1a. dapat disimpulkan bahwa fungsi survival dengan estimasi parameter metode Bayesian SELF menghasilkan nilai survival yang bergerak mendekati nol, sesuai dengan karakteristik dari fungsi survival. Gambar 1b, menunjukkan bahwa nilai hazard dari fungsi hazard dengan estimasi parameter metode Bayesian SELF bergerak naik secara linear terhadap waktu. Hasil dari nilai hazard pada penelitian ini sesuai dengan karakteristik dari distribusi Rayleigh.

\section{KESIMPULAN}

Berdasarkan hasil analisis yang telah dipaparkan maka dapat diambil kesimpulan sebagai berikut:

1. Estimasi parameter distribusi Rayleigh dengan metode Bayesian SELF adalah:

$$
\begin{aligned}
\hat{s}_{B S}\left(t_{i} ; \hat{\theta}_{B S}\right) & =\exp \left(-\frac{t_{i}^{2}}{2 \theta^{2}}\right) \\
& =\exp \frac{2\left(\frac{-t_{i}^{2}}{\left(\sum_{i=1}^{n} t_{i}^{2}\right)^{\frac{1}{2}}\left(2^{\frac{1}{2}}\right) \Gamma\left(n-\frac{1}{2}\right)}\right)^{2}}{\hat{h}_{B S}\left(t_{i} ; \hat{\theta}_{B S}\right)}=\frac{t_{i}}{\theta^{2}} \\
& =\frac{t_{i}}{\left(\frac{\Gamma(n-1)}{\left.\left(\sum_{i=1}^{n} t_{i}^{2}\right)^{\frac{1}{2}}\left(2^{\frac{1}{2}}\right) \Gamma\left(n-\frac{1}{2}\right)\right)^{2}}\right.}
\end{aligned}
$$


2. Distribusi Rayleigh ini dapat digunakan dalam mengestimasi parameter model survival metode Bayesian SELF dan diterapkan pada data survival, yang pada penelitian ini menggunakan data penderita kanker paru-paru. Nilai dari parameter $\hat{\theta}_{B S}$ untuk metode Bayesian SELF adalah 247,6352. Nilai survival pada hasil penelitian terus turun mendekati nol, hingga pada hari ke 791 nilai survival sebesar 0,006087581 sedangkan nilai hazard semakin besar dan bernilai 1,289887 $\times 10^{-2}$. Nilai survival yang terus mendekati nol sesuai dengan karakteristik dari fungsi survival, sedangkan nilai hazard yang naik secara linear terhadap waktu sesuai dengan karakteristik dari fungsi hazard.

\section{DAFTAR PUSTAKA}

[1] Kleinbaum DG, Klein M. Survival Analysis: A Self-Learning Text. New York: Springer Science Business Media Inc; 2005.

[2] Lee ET, Wang JW. Statistical Methods for Survival Data Analysis. Canada: A John Wiley \& Sons Inc; 2003

[3] Bolstad, WM. Introduction to Bayesian Statistics Second Edition. Amerika: A John Wiley \& Sons Inc; 2007

[4] Guure CB, Ibrahim NA. Bayesian Analysis Survival Function and Failure Rate of Weibull Distribution with Cencored Data. Journal Mathematical Problem in Engineering. 2012. Vol 2012. Articel ID 329489.

[5] Dey S, Dey T. Rayleigh Distribution Revisited via Extension of Jeffrey's Prior Information and a New Loss Function. Statistical Journal. 2011; 9(3): 213-226.

[6] Dey S, Maiti SS. Bayesian Estimation of the Parameter of Rayleigh Distribution Under the Extended Jeffrey's Prior. Electronic Journal of Applied Statistical Analysis. 2012; 5(1): 44-59.

[7] Ahmed A. Ahmad SP, Reshi JA. Bayesain Analysis of Rayleigh Distribution. International Journal of Scientific and Research Publication. 2013; 3(10): 1-9.

EKA RIZKI WAHYUNI

SETYO WIRA RIZKI

HENDRA PERDANA
: FMIPA Untan Pontianak, ekarizkiwahyuni37@gmail.com

: FMIPA Untan Pontianak, setyo.wirarizki@math.untan.ac.id

: FMIPA Untan Pontianak, hendra.perdana@math.untan.ac.id 